Seaman, G. R. (1954). J. gen. Microbiol. 11, 300-306.

\title{
Pyruvate Oxidation by Extracts of Tetrahymena pyriformis
}

\author{
BY G. R. SEAMAN \\ Carter Physiology Laboratory, University of Texas Medical Branch, \\ Galveston, Texas, U.S.A.
}

SUMMARY: Tetrahymena pyriformis $\mathrm{S}$ has an enzyme system which splits pyruvic oxime. This permitted the use of hydroxylamine as non-enzymic acyl acceptor in assaying pyruvate oxidation enzymes in crude extracts. Removal of thioctic acid from crude preparations of tetrahymena pyruvic oxidase by alumina treatment resulted in decreased acyl group formation, but did not affect the rate of oxidation in the presence of ferricyanide. Purification of the oxidase removed both the oximesplitting system and the enzyme which is necessary for removal of thioctic acid from enzymes by the alumina procedure.

Removal of thioctic acid from crude preparations of $\alpha$-keto acid oxidases of tetrahymena decreases acylation activity as measured by following the formation of acyl-Coenzyme A by the hydroxamic method (Seaman, 1952, 1953). It was also observed that the addition of thioctic acid restored activity. Since under the conditions employed, hydroxylamine may perhaps be a rather nonspecific indicator of acyl-Coenzyme $\mathbf{A}$ formation, it was desirable to extend the observations to assure that the observed effects are referable to the pyruvate system.

\section{METHODS}

Enzyme preparation. Tetrahymena pyriformis $\mathbf{S}$ was grown as previously described (Seaman, 1953). The carboys in which the organisms had grown for $72 \mathrm{hr}$. were placed in the cold room $\left(4^{\circ}\right)$ and the organisms allowed to settle' overnight. The clear supernatant was siphoned off and the cells were concentrated by centrifugation at $850 \mathrm{~g}$ for $15 \mathrm{~min}$. at $4^{\circ}$. After three washes in $0.01 \mathrm{M}$-phosphate buffer ( $\mathrm{pH} \mathrm{7.4}$ ) the concentrate was ground with twice its wet weight of quartz on an automatic grinder for $\mathbf{3 0}$ min. and extracted with 5 vol. of $0.01 \mathrm{~m}$-phosphate buffer ( $\mathrm{pH} 7 \cdot 4$ ) for an additional $30 \mathrm{~min}$. The suspension was clarified by centrifugation at $5000 \mathrm{~g}$ for $15 \mathrm{~min}$.

Preparations of pyruvic oxidase at three stages of purity were obtained by treating the turbid suspension according to the procedure of Jagannathan \& Schweet (1952) for purification of the enzyme from pigeon breast muscle. Precipitation of the extract at $\mathrm{pH} \mathrm{5.4}$ provided the crudest preparation examined (fraction 1). Later, freezing and thawing (fraction 2 ) and fractionation at $\mathrm{pH} 6 \cdot 2$ (fraction 3 ) provided purer preparations.

Assay procedures. The ferricyanide manometric assay (FCNM assay) was essentially as described by Jagannathan \& Schweet (1952). The incubation mixture contained, in a volume of $3.0 \mathrm{ml}$., $100 \mu$ mole sodium pyruvate, $30 \mu$ mole $\mathrm{NaHCO}_{3}, 20 \mu$ mole $\mathrm{MgCl}_{2}, 200 \mu \mathrm{g}$. neutralized ( $\mathrm{pH} \mathrm{6.0)}$ cocarboxylase, $100 \mu$ mole $\mathrm{K}_{3} \mathrm{Fe}(\mathrm{CN})_{6}$, and enzyme. Activity is expressed as $\mu$ mole of $\mathrm{CO}_{2}$ 
evolved/hr./10 mg. protein. Manometric runs were at $32^{\circ}$ under $\mathrm{CO}_{2}$. In this assay, analyses show a constant $\mathrm{CO}_{2}$ /pyruvate ratio of $2 \cdot 06-2 \cdot 23$. The consistent difference between these values and the theoretical value of 3 , indicates a non-oxidative side reaction of pyruvate, whose nature is yet uncertain.

The hydroxamic acid assay (HXMA assay) was carried out in mixtures containing, in $1.4 \mathrm{ml}$., $100 \mu$ mole pyruvate, $10 \mu$ mole $\mathrm{MgCl}_{2}, 100 \mu \mathrm{g}$. neutralized cocarboxylase, 20 units of Coenzyme A (Co A), $200 \mu$ mole tris(hydroxymethyl)aminomethane (Tris) (pH 7.4), $10 \mu$ mole cysteine, 0.10 $\mu$ mole diphosphopyridine nucleotide (DPN), 800 units of lactic dehydrogenase, $200 \mu$ mole hydroxylamine, and tetrahymena enzymes. Use of high hydroxylamine concentrations assured measurement of the non-enzymic acyl transfer from Co A to the trapping agent (Chou \& Lipmann, 1952). Although added hydrogen carriers are not required when the crude fraction 1 is assayed (Seaman, 1953), fractions 2 and 3 require the electron acceptor system; lactic dehydrogenase and DPN were thus routinely included. The assay was carried out under nitrogen, and activity is expressed as $\mu$ mole hydroxamic acid formed/hr./ $10 \mathrm{mg}$. protein.

In the acetyl phosphate assay (ACP assay), the non-enzymic acyl acceptor was replaced by 10 units of transacetylase, and $100 \mu$ mole phosphate buffer ( $\mathrm{pH} \mathrm{7 \cdot 4)}$ was used in place of Tris buffer. Added lactic dehydrogenase was also omitted from this assay since the bacterial extract used as the source of transacetylase contained sufficient lactic enzyme. Incubations were carried out under nitrogen for $60 \mathrm{~min}$. at $32^{\circ}$. Acetyl phosphate formation was measured at the completion of the run and activity is expressed as $\mu$ mole acetyl phosphate formed/hr./10 mg. protein.

Analytical methods. Acetyl phosphate and hydroxamic acid were measured as described by Lipmann \& Tuttle $(1945 a, b)$. Protein content of enzymes was measured by ultraviolet absorption (Kalckar, 1947). The thioctic acid content of enzymes was determined by the growth response of tetrahymena or by the manometric assay procedure of Gunsalus, Dolin \& Struglia (1952).

Preparations. Lactic dehydrogenase was crystallized from pig heart (Meister, 1952) and was assayed according to Mehler, Kornberg, Grisolia \& Ochoa (1948). Transacetylase was supplied by a dialysed extract(Korkes, Stern, Gunsalus \& Ochoa, 1950) of Streptococcus faecalis strain 10C1. The streptococci were grown in defined medium low in thioctic acid (Gunsalus et al. 1952); the method of Stadtman (1952) was used to assay the preparations. Sodium pyruvate was prepared by the method of Robertson (1942). Cocarboxylase, DPN, and Co A were obtained commercially. Cultures of $S$. faecalis were kindly supplied by Dr I. C. Gunsalus, and thioctic acid was generously furnished by Dr E. L. R. Stokstad.

\section{RESULTS AND DISCUSSION}

Table 1 shows that the tetrahymena oxidase at the degree of purity of fraction 1 readily oxidized pyruvate in the ferricyanide system and formed acetyl-Co $\mathrm{A}$ as indicated by both the hydroxylamine trapping assay and by the formation of acetyl phosphate. Since in the hydroxamic acid assay, the 
incubation mixture contained both $\alpha$-keto acid and hydroxylamine, which rapidly react to form the oxime, it appears that contrary to the condition in mammalian tissues, the protozoan oxidase utilizes the oxime derivative as readily as it does the $\alpha$-keto acid. But fraction 1, when repeatedly frozen and thawed to yield fraction 2 , yielded preparations which had only slight activity

Table 1. Activity of pyruvic oxidase fractions of different purity and the effect of alumina treatment.

Conditions are described in text.

\begin{tabular}{l}
\multicolumn{1}{c}{$\begin{array}{c}\text { Enzyme fraction } \\
\text { and treatment }\end{array}$} \\
Fraction 1 \\
None \\
Alumina \\
Alumina $+7 \cdot 5 \mathrm{~m} \mu \mathrm{g}$. thioctic acid \\
Fraction 2 \\
None \\
Alumina \\
Alumina $+21 \mathrm{~m} \mu \mathrm{g}$. thioctic acid \\
Fraction 3 \\
None \\
Alumina
\end{tabular}

\begin{tabular}{|c|c|c|c|}
\hline \multirow{2}{*}{$\begin{array}{c}\text { Thioctic } \\
\text { acid } \\
\text { content } \\
\text { of } \\
\text { enzyme } \\
\text { (m } \mu \text { g./mg. } \\
\text { protein) }\end{array}$} & \multicolumn{3}{|c|}{ Pyruvic oxidase activity } \\
\hline & $\begin{array}{c}\text { FCNM } \\
\text { assay }\end{array}$ & $\begin{array}{c}\text { HXMA } \\
\text { assay }\end{array}$ & $\begin{array}{l}\text { ACP } \\
\text { assay }\end{array}$ \\
\hline 37 & $3 \cdot 8$ & 1.8 & $1 \cdot 1$ \\
\hline 16 & 3.9 & 0.8 & 0.4 \\
\hline 16 & $3 \cdot 6$ & 1.5 & 0.8 \\
\hline 96 & $10 \cdot 4$ & 0.4 & $3 \cdot 2$ \\
\hline 50 & $10 \cdot 1$ & - & 1.5 \\
\hline 50 & $9 \cdot 4$ & - & $2 \cdot 7$ \\
\hline 139 & $18 \cdot 3$ & - & $5 \cdot 0$ \\
\hline 137 & $19 \cdot 1$ & - & $5 \cdot 0$ \\
\hline
\end{tabular}

in the non-enzymic acyl acceptor assay system; activity of fraction 2 remained high in the ferricyanide and acetyl phosphate assays (Table 1). It thus appears that rather than being capable of utilizing oximes per se, the crude tetrahymena preparation (fraction 1) enzymically split the oxime, making both pyruvate and hydroxylamine available. The oxime-splitting system was in the material which was removed by the freezing and thawing procedure used in the preparation of fraction 2. Addition of material precipitated in this step to fraction 2, however, did not restore ability to react; the previously active protein was apparently denatured.

Additional evidence of an oxime-splitting system in crude preparations was afforded by pyruvate analyses of incubation mixtures containing fraction 1 . Before addition of fraction 1 , the hydroxamic acid assay reaction mixture gave a negative test for pyruvate with phenylhydrazine; all available pyruvate had combined with hydroxylamine. Ten minutes after the addition of the enzyme, traces of pyruvate were detected, and subsequent analyses during the entire $60 \mathrm{~min}$. incubation period continued to indicate traces of the $\alpha$-keto acid. In mixtures containing samples of fraction 1 inactivated by heating at $65^{\circ}$ for $20 \mathrm{~min}$., no pyruvate was detected. Since only small amounts of the added pyruvate are measurable at any one time, the equilibrium of the reaction: pyruvic oxime $+\mathrm{H}_{2} \mathrm{O} \rightleftharpoons$ pyruvate + hydroxylamine, is well to the left. In the presence of active pyruvic oxidase the equilibrium may be shifted to the right 
as the $\alpha$-keto acid is consumed and as hydroxylamine reacts with acyl groups. Oxime splitting must be slightly more rapid than pyruvate utilization since slight amounts of pyruvate were found throughout the incubation period. If the rate of the oxime system were slower, assays by the hydroxamic acid method would be lower than those obtained by the other procedures; Table 1 shows that this was not the case. According to theory, responses in the acetyl phosphate assay and in the hydroxamic acid assay should be equal, and about one-half that obtained in the ferricyanide assay. The observed lower response in the acetyl phosphate system resulted from competition between the Streptococcus faecalis extract and the tetrahymena enzyme for pyruvate. Although the streptococcal extract did not oxidize pyruvate via acetyl-Co A, significant amounts of acetylmethylcarbinol were formed from the $\alpha$-keto acid.

With crude tetrahymena preparations one can therefore use hydroxylamine as the non-enzymic acceptor in the presence of $\alpha$-keto acids. However, with purer preparations, in which the oxime-splitting system has been removed or destroyed (e.g. by repeated freezing and thawing), enzymic acceptor systems are needed in order to follow acyl-Co $\mathbf{A}$ formation.

Although alumina treatment (Seaman, 1953) of fractions 1 and 2 decreased the formation of acetyl-Co $A$, the treatment did not decrease the rate of pyruvate oxidation in the ferricyanide system. Assay of the fractions for thioctic acid demonstrated the actual decrease in concentration of co-factor after alumina treatment. The alumina procedure therefore, while not completely removing thioctic acid from the system, decreased the concentration of co-factor below enzyme saturation. Activity of the alumina-treated systems was readily restored by the addition of synthetic thioctic acid to incubation mixtures; $6-10 \mathrm{~m} \mu \mathrm{g}$. provided enough thioctic acid to reverse the alumina effect with fraction 1 (Fig. 1). With fraction 2, the optimal amount of thioctic acid was $20-28 \mathrm{~m} \mu \mathrm{g}$.

The findings that thioctic acid is not involved in the oxidation of pyruvate in the presence of ferricyanide is in agreement with previous reports (Seaman, 1953; Reed \& DeBusk, 1953). The ferricyanide assay system gives an overall measure of the release of $\mathrm{CO}_{2}$ involved in the oxidative decarboxylation of pyruvate (the decarboxylase and the initial oxidation of the two-carbon intermediate). This may be formulated as:

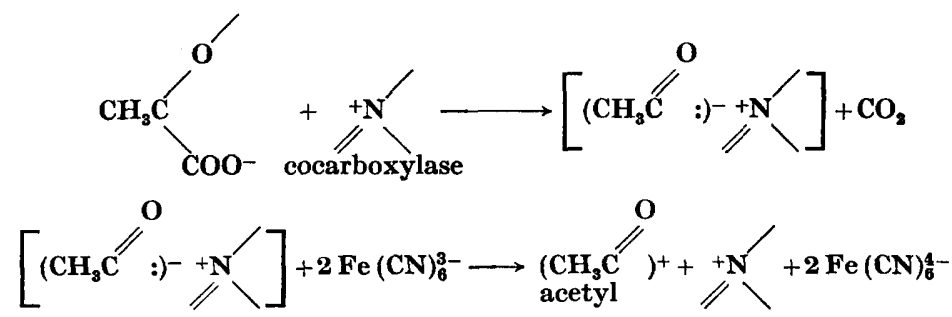

That ferricyanide is actually reduced in the assay mixture is indicated in Table 2. In these experiments, the reactants of the standard ferricyanide assay mixture, with the exception of the ferricyanide, were added to cuvettes 


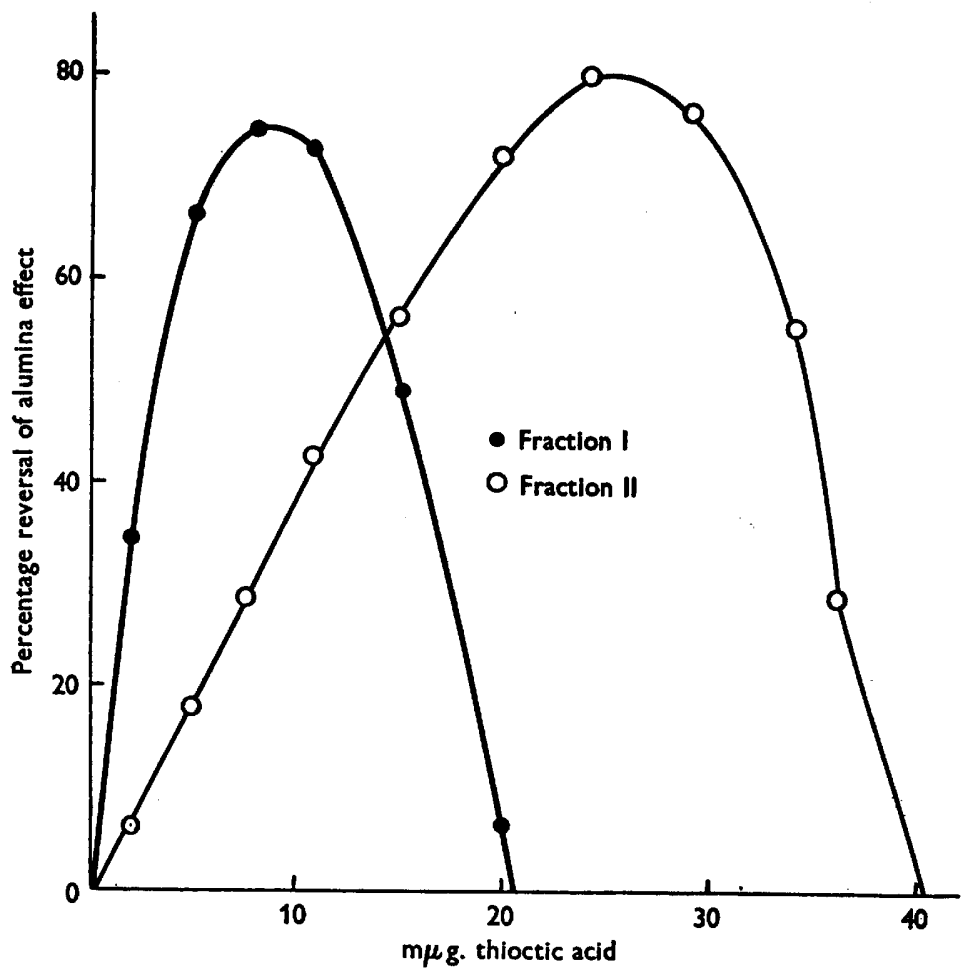

Fig. 1. Reversal of alumina effect by added thioctic acid. Activity measured in the ACP assay as described in text.

Table 2. Ferricyanide reduction by pyruvic oxidase-Fraction 1

\section{from tetrahymena}

Complete incubation mixture contained in $1.0 \mathrm{ml} .: 33 \mu$ mole sodium pyruvate, $10 \mu$ mole $\mathrm{NaHCO}_{3}, 6.5 \mu \mathrm{mole} \mathrm{MgCl}_{2}, 72 \mu \mathrm{g}$. neutralized cocarboxylase, and enzyme. After incubation at $24 \pm 1.5^{\circ}$ for 5 min. the reaction was started by the addition of $0.5 \mu$ mole $K_{3} \mathrm{Fe}(\mathrm{CN})_{6}$. Reduction was followed at wavelength $410 \mathrm{~m} \mu$. in the Beckman DU spectrophotometer.

\section{Incubation mixture}

Untreated enzyme

$$
\text { Complete }
$$

$+0 \cdot 1 \mu$ mole DPN

$+7.5 \mathrm{~m} \mu \mathrm{g}$. thioctic acid

+5 units Co A

+5 units Co $A+10 \mu$ mole cysteine

- pyruvate

- cocarboxylase

Alumina-treated enzyme Complete

$+7.5 \mathrm{~m} \mu \mathrm{g}$. thioctic acid

\section{Ferricyanide} reduction $\mu$ mole $\times 10^{3} / \mathrm{min} . / 10 \mathrm{mg}$. protein

42

41

38

40

42

2

8

40 
and pre-incubated at room temperature $\left(24 \pm 1 \cdot 5^{\circ}\right)$ for 5 min. The reaction was then started by the addition of ferricyanide and the rate of reduction was followed in the Beckman DU spectrophotometer. As is the case with the pigeon enzyme system, the addition of Co A, DPN, or thioctic acid were without effect. In some experiments with $\mathrm{Co} A$, cysteine was added to the reaction mixture to keep the coenzyme in the reduced form; this had no effect on the rate of reduction of ferricyanide. However, when the enzyme was omitted, there was, as expected, a rapid reduction of ferricyanide by the cysteine. It thus appeared that during the pre-incubation period of the assay, cysteine reacted with disulphide links in the enzyme protein and thus, as cystine, became unavailable to reduce ferricyanide. The reduced thiol groups of the protein would then maintain Co A in the reduced form, but could not reduce ferricyanide. This was verified by incubating heat-inactivated samples of fraction $2\left(60^{\circ}\right.$ for $15 \mathrm{~min}$.) with $0.0063 \mathrm{M}$-cysteine for $5 \mathrm{~min}$. and then dialysing anaerobically against running nitrogen-saturated water for $48 \mathrm{hr}$. The resulting protein solution replaced cysteine in both the arsenolytic reaction with Streptococcus faecalis extracts, and in the acetate-activating reaction with crude pigeon liver extracts, but did not reduce an aqueous solution of ferricyanide.

The thioctic acid independence of the initial stage of pyruvate oxidation as formulated above appears to preclude the formation of an addition product of thioctic acid and pyruvate as an early step in oxidative decarboxylation; such a compound has been proposed by Calvin (1953).

Table 1 also shows that while the alumina treatment removed thioctic acid from fractions 1 and 2 , with fraction 3 the procedure did not affect the rate of pyruvate oxidation or the thioctic acid content of the enzyme. This indicated that some component of the system which was required for the alumina effect, and which was present in crude material, was removed in preparing fraction 3. This is probably analogous to the removal during the purification of pigeon liver enzymes of an enzyme which split thioctic acid from enzyme protein (Seaman, 1954). The liberated thioctic acid was then adsorbed and removed by the alumina. However, unlike pigeon extracts, addition of the two subfractions obtained during this step to the resultant fraction 3, either singly or together, failed to restore ability of the fraction to show an alumina effect.

This investigation was aided by grants from the National Institutes of Health (G-3364), the National Vitamin Foundation, and by a contract (Nonr-994(00)) between the Office of Naval Research and the University of Texas. The author is grateful to Dr S. H. Hutner for his helpful reading of the manuscript.

\section{REFERENCES}

Calvin, M. (1953). The quantum conversion in photosynthesis. Chem. Engng Neres, $31,1735$.

Сноu, T. C. \& Lipmann, F. (1952). Separation of acetyl transfer enzymes in pigeon liver extract. J. biol. Chem. 196, 89.

Gunsalus, I. C., Dolin, M. I. \& Struglia, L. (1952). Pyruvic acid metabolism. III. A manometric assay for pyruvate oxidation factor. J. biol. Chem. 194, 849. 
Jagannathan, V. \& Schweet, R. S. (1952). Pyruvic oxidase of pigeon breast muscle. I. Purification and properties of the enzyme. J. biol. Chem. 196, 551.

KaLCKAR, H. M. (1947). Differential spectrophotometry of purine compounds by means of specific enzymes. III. Studies on the enzymes of purine metabolism. J. biol. Chem. 167, 461.

Korkes, S., Stern, J. R., Gunsalus, I. C. \& Ochoa, S. (1950). Enzymatic synthesis of citrate from pyruvate and oxaloacetate. Nature, Lond. 166; 439.

Lipmanv, F. \& TUTtue, L. C. $(1945 a)$. A specific micromethod for the determination of acylphosphates. J. biol. Chem. 159, 21.

Lipmann, F. \& TUtrte, L. C. $(1945 b)$. The detection of carboxyl groups with hydroxylamine as interceptor. J. biol. Chem. 161, 415.

Meister, A. (1952). Crystalline lactic dehydrogenase, in Biochem. Prep. ed. E. E. Snell 2, 18. London: Chapman and Hall.

Mehler, A. H., Kornberg, A., Grisolia, S. \& OchoA, S. (1948). The enzymatic mechanisms of oxidation-reductions between malate or isocitrate and pyruvate. J. biol. Chem. 174, 961.

Reed, L. J. \& DeBusk, B. (1953). Mechanism of enzymatic oxidative decarboxylation of pyruvate. J. Amer. chem. Soc. 75, 1261.

Robertson, W. (1942). The preparation of sodium pyruvate. Science, 96, 93.

Seaman, G. R. (1952). Role of protogen in the oxidation of pyruvic acid. Proc. Soc. Exp. Biol., N.Y. 80, 308.

Seaman, G. R. (1953). Role of thioctic acid in the transfer of acyl groups. Proc. Soc. Exp. Biol., N.Y. 82, 184.

Seaman, G. R. (1954). Participation of thioctic acid in the acetate-activating reaction. J. Amer. chem. Soc. 76, 1712.

Stadtman, E. R. (1952). The purification and properties of phosphotransacetylase. J. biol. Chem. 196, 527.

Stumpf, P. K., Zarudnaya, K. \& Green, D. E. (1947). Pyruvic and $\alpha$-ketoglutaric oxidase of animal tissue. J. biol. Chem. 167, 817.

(Received 8 May 1954) 